\title{
Psychosocial Correlates of Objective, Performance-Based, and Patient-Reported Physical Function Among Patients with Heterogeneous Chronic Pain
}

This article was published in the following Dove Press journal:

Journal of Pain Research

\author{
Jonathan Greenberg (1D ${ }^{1,2}$ \\ Ryan A Mace $\mathbb{D}^{1,2}$ \\ Paula J Popok (D) \\ Ronald J Kulich (DD ${ }^{2,3}$ \\ Kushang V Patel (D) ${ }^{4}$ \\ John W Burns ${ }^{5}$ \\ Tamara J Somers (1D) \\ Francis J Keefe $\mathbb{D D}^{7}$ \\ Michael E Schatman (iD ${ }^{8,9}$ \\ Ana-Maria Vranceanu (D) ${ }^{1,2}$ \\ 'Integrated Brain Health Clinical and \\ Research Program, Massachusetts \\ General Hospital, Boston, MA, USA; \\ ${ }^{2}$ Harvard Medical School, Boston, MA, \\ USA; ${ }^{3}$ Center for Pain Medicine, \\ Massachusetts General Hospital, Boston, \\ MA, USA; ${ }^{4}$ Department of \\ Anesthesiology \& Pain Medicine, \\ University of Washington, Seattle, WA, \\ USA; ${ }^{5}$ Division of Behavioral Sciences, \\ Rush Medical College, Chicago, IL, USA; \\ ${ }^{6}$ Psychiatry \& Behavioral Sciences, Duke \\ University School of Medicine, Durham, \\ NC, USA; ${ }^{7}$ Department of Medicine, \\ Duke University School of Medicine, \\ Durham, NC, US; ${ }^{8}$ Department of \\ Diagnostic Sciences, Tufts University \\ School of Dental Medicine, Boston, MA, \\ USA; ${ }^{9}$ Department of Public Health and \\ Community Medicine, Tufts University \\ School of Medicine, Boston, MA, USA
}

Correspondence: Ana-Maria Vranceanu Email avranceanu@mgh.harvard.edu

\begin{abstract}
Background: Improving all aspects of physical function is an important goal of chronic pain management. Few studies follow recent guidelines to comprehensively assess physical function via patient-reported, performance-based, and objective/ambulatory measures.

Purpose: To test 1) the interrelation between the 3 types of physical function measurement and 2) the association between psychosocial factors and each type of physical function measurement.
\end{abstract}

Methods: Patients with chronic pain (N=79) completed measures of: 1) physical function (patient-reported disability; performance-

based 6-minute walk-test; objective accelerometer step count); 2) pain and non-adaptive coping (pain during rest and activity, pain-catastrophizing, kinesiophobia); 3) adaptive coping (mindfulness, general coping, pain-resilience); and 4) social-emotional dysfunction (anxiety, depression, social isolation and emotional support). First, we tested the interrelation among the 3 aspects of physical function. Second, we used structural equation modeling to test associations between psychosocial factors (pain and non-adaptive coping, adaptive coping, and social-emotional dysfunction) and each measurement of physical function.

Results: Performance-based and objective physical function were significantly interrelated $(r=0.48, p<0.001)$ but did not correlate with patient-reported disability. Pain and nonadaptive coping $(\beta=0.68, p<0.001)$, adaptive coping $(\beta=-0.65, p<0.001)$ and socialemotional dysfunction $(\beta=0.65, p<0.001)$ were associated with patient-reported disability but not to performance-based or objective physical function ( $\mathrm{ps}>0.1$ ).

Conclusion: Results suggest that patient-reported physical function may provide limited information about patients' physical capacity or ambulatory activity. While pain and nonadaptive reactions to it, adaptive coping, and social-emotional dysfunction may potentially improve patient-reported physical function, additional targets may be needed to improve functional capacity and ambulatory activity.

Trial Registration: ClinicalTrials.gov NCT03412916.

Keywords: physical function, chronic pain, six-minute walk test, accelerometer, psychosocial factors

\section{Introduction}

Chronic pain is financially costly, widespread ${ }^{1}$ and decreases physical function. Most patients with chronic pain report challenges with physical function and 
activity-related increased symptoms. ${ }^{2}$ As a result, chronic pain treatments are increasingly focused on improving physical function. ${ }^{3,4}$

Most physical function research in chronic pain has been focused on patient-reported outcomes (PROs). ${ }^{5-7}$ However, physical function is a multidimensional construct that encompasses more than an individual's perception of functioning. Consistently, the Initiative on Methods, Measurement, and Pain Assessment in Clinical Trials (IMMPACT) ${ }^{8,9}$ and the International Classification of Functioning, Disability and Health (ICF) ${ }^{10}$ recommend comprehensively assessing physical function, with PROs, performance-based (which capture functional capacity during a time-limited standard test), and objective assessments (ambulatory measurement of daily step-count via accelerometers across a specified time period). ${ }^{11}$

Studies evaluating the relationship between the different aspects of physical function in chronic pain have generally found conflicting results on the association between PROs and accelerometer-measured physical function. ${ }^{12-14}$ They found a small to moderate association between PROs and performanced based physical function, ${ }^{15-18}$ as well as between accelerometer-measured physical function and PROs. ${ }^{19,20}$ Currently, only 2 published papers looked at all 3 physical function measures within 1 study and found support for an association between PROs and performance-based function but little or no support for associations with step-count. ${ }^{21,22}$

Treatments aimed at improving physical function in chronic pain typically target psychosocial factors such as pain, coping, and social-emotional factors, ${ }^{23-25}$ which are associated with improvement in PROs. ${ }^{8,26}$ However, it is unclear whether targeting these constructs also improves performance-based and objective/ambulatory-measured physical function, as prior studies found mixed results for associations with performance-based physical function $^{21,27,28}$ and step-count physical function. ${ }^{12,21,28-30}$

The success of chronic pain treatments lies in targeting factors that can improve all facets of physical function. ${ }^{31,32}$ To inform such pain treatments, the association between all facets of physical function, as well as their relationship with psychosocial factors typically targeted in chronic first needs to be established. Consistently, we aimed to test, within 1 model, the association among psychosocial factors typically targeted in chronic pain trials with PROs, performance-based, and objective physical function. We examined a theoretically driven model of latent psychosocial factors (pain and non-adaptive coping, adaptive pain coping and social-emotional dysfunction) and modeled their relationships to these 3 physical function facets. First, we wanted to understand to which extent PROs, performance-based and objective physical function are interrelated. Next, we explored cross-sectional associations of the 3 latent constructs with the 3 physical function facets.

\section{Method}

\section{Participants and Recruitment}

We analyzed baseline data from 2 sequential pilot mindbody clinical trials. ${ }^{33,34}$ The trials constituted 2 phases of the same study, tested different iterations of the same mind-body interventions, targeted the same population and used identical inclusion/exclusion criteria, referral sources, and recruitment materials. Participants were recruited through direct referrals from the Center for Pain Medicine at Massachusetts General Hospital, online mailing lists and advertisements within Partners Healthcare. Recruitment occurred between July 2018 and September 2019. Inclusion criteria were: 1) 18 years of age or older, 2) nonmalignant self-reported chronic pain for at least 3 months, consistent with the definition of chronic pain as persistent or recurrent pain lasting longer than 3 months, ${ }^{35} 3$ ) ability to walk for at least 6 minutes, 4) access to a mobile device with Bluetooth $4.0,5)$ if on pain or psychotropic medication, being on a stable dose for the past 3 months, and 6) cleared for participation by a medical doctor. Exclusion criteria were: 1) medical illness that was expected to worsen over the following 6 months, 2) active suicidality or untreated and serious psychiatric illness, 3) current untreated substance use disorder, 4) participation in meditation or yoga practice for more than 45 minutes a week during the prior 6 months, 5) using a Fitbit device in the prior 6 months, and 6) $>30 \mathrm{~min}$ daily of regular physical exercise. The mind-body physical activity programs aimed to improve PRO, performancebased and objective physical function through teaching mind-body skills (eg, breathing meditation, body scan, mindfulness), pain-specific cognitive-behavioral skills (eg, goal setting, behavioral activation, adaptive thinking), and physical restoration skills (eg, quota-based pacing). We tested our research questions using baseline data collected prior to program participation.

A total of 95 participants met inclusion and exclusion criteria across the 2 trials. Participants had a mean age of 50.69 years $(\mathrm{SD}=14.68)$, were predominantly female $(67 \%)$, white $(76 \%)$, non-Hispanic $(85 \%)$ (Table 1). The 
Table I Demographics

\begin{tabular}{|c|c|}
\hline \multirow[t]{2}{*}{ Age (M (SD)) } & $50.69(14.68)$ \\
\hline & $\mathbf{N}(\%)$ \\
\hline \multicolumn{2}{|l|}{ Gender } \\
\hline Male & $31(32.6 \%)$ \\
\hline Female & $64(67.4 \%)$ \\
\hline \multicolumn{2}{|l|}{ Ethnicity } \\
\hline Hispanic or Latino/Latina & $12(12.6 \%)$ \\
\hline Not Hispanic or Latino/Latina & 81 (85.3\%) \\
\hline Missing & $2(2.1 \%)$ \\
\hline \multicolumn{2}{|l|}{ Race } \\
\hline White & $72(75.8 \%)$ \\
\hline American Indian/Alaskan Native & $2(2.1 \%)$ \\
\hline Asian & $6(6.3 \%)$ \\
\hline Black/African American & $8(8.4 \%)$ \\
\hline More Than One Race & 7 (7.4\%) \\
\hline \multicolumn{2}{|l|}{ Marital Status } \\
\hline Single, never married & $34(35.8 \%)$ \\
\hline Living with significant other & II (II.6\%) \\
\hline Married & $27(28.4 \%)$ \\
\hline Separated/Divorced & $19(20 \%)$ \\
\hline Widowed & $4(4.2 \%)$ \\
\hline \multicolumn{2}{|l|}{ Employment } \\
\hline Employed full-time & $26(27.4 \%)$ \\
\hline Employed part-time & $12(12.6 \%)$ \\
\hline Going to school full or part time & $3(3.2 \%)$ \\
\hline Retired & 17 (I7.9\%) \\
\hline Unemployed & $20(21 \%)$ \\
\hline Other & 17 (I7.9\%) \\
\hline \multicolumn{2}{|l|}{ Education } \\
\hline High school (12 years) & $14(14.7 \%)$ \\
\hline Some college/Associates degree ( $<16$ years) & $28(29.5 \%)$ \\
\hline Completed college (16 years) & $20(21.1 \%)$ \\
\hline Graduate/professional degree ( $>16$ years) & $33(34.7 \%)$ \\
\hline \multicolumn{2}{|l|}{ Pain Type } \\
\hline Multi-site & $65(68.4 \%)$ \\
\hline Back pain & $10(10.5 \%)$ \\
\hline Neck pain & $3(3.2 \%)$ \\
\hline Fibromyalgia & $2(2.1 \%)$ \\
\hline Other & $14(14.7 \%)$ \\
\hline Missing & $\mathrm{I}(\mathrm{I} . \mathrm{I} \%)$ \\
\hline Pain duration (median) & 10 years \\
\hline
\end{tabular}

most common marital, education and employment statuses were single or never married (36\%), holding a graduate or professional degree (35\%), and being fully employed (27\%), respectively. Participants reported a median pain duration of 10 years $(\mathrm{SD}=10.48 ; \min =3$ months; $\max =60$ years) and the majority (68\%) had more than 1 type of chronic pain.

After providing written informed consent, participants completed a battery of PROs assessing physical function, pain and non-adaptive coping, and socialemotional dysfunction (see Measures), and underwent the 6-minute walk test $\left(6 \mathrm{MWT}^{36}\right)$. At the end of the baseline visit, participants received a wGT3X-BT ActiGraph accelerometer (ActiGraph, LLC, Fort Walton Beach, FL, USA) and were instructed to wear it during all waking hours over their right hip. They were also instructed to maintain their regular levels of activity, and to fill out a daily device-wear and activity log. Participants were offered the option to receive text message reminders to wear the ActiGraph devices. All study procedures were approved by the Institutional Review Board at Massachusetts General Hospital and were conducted in accordance with the Declaration of Helsinki.

\section{Measures}

We administered reliable and valid measures that captured the constructs of interest and are routinely used in chronic pain clinical trials. In line with our research question and recent IMMPACT criteria, we assessed PROs, performancebased (6MWT) and objective/ambulatory (step-count) physical function. We combined the rest of our psychosocial measures into categories based on conceptual overlap and prior research. The first category included pain (ie, pain during rest and activity) and non-adaptive coping (ie, pain catastrophizing, kinesiophobia). These factors were grouped together because they are all negative responses to an initial nociceptive stimulus. ${ }^{37,38}$ The second category consisted of adaptive coping with pain (ie, general coping strategies, pain resilience, and mindfulness). Positive psychology research indicates that these factors provide a useful framework for assessing strengths in individuals who experience chronic pain, beyond the absence of the non-adaptive reactivity patterns in the first category. ${ }^{39,40}$ We grouped these factors together since cultivating mindfulness and relaxation is an established adaptive coping strategy in the face of pain and difficulty. $^{41-43}$ The third category consists of socialemotional dysfunction (anxiety, depression social isolation, emotional support), as these constructs are often interrelated and are frequently coupled in relevant literature. ${ }^{44-46}$

\section{Objective Physical Function}

We measured average daily step count over the course of 7 days with a wGT3X-BT ActiGraph accelerometer. ${ }^{47}$ 
ActiGraph settings are detailed in previous studies. ${ }^{33,34}$ Participants were instructed to wear the ActiGraph during all waking hours over their right hip using an elastic belt for one week, except when in water (eg, bathing or swimming). The mean daily ActiGraph wear time in our sample was 12.2 hours per day. Data were stored, cleaned and analyzed with ActiLife software. The devices recorded counts in epochs of 30 seconds. ${ }^{48}$ We defined non-wear time as 90 or more consecutive minutes having no activity counts. ${ }^{49}$ We allowed 2 minutes or less of activity counts between 0 and $100,{ }^{50}$ and any wear periods shorter than 10 minutes long were ignored. A staff member verified the validity of ActiGraph wear time data and compared them with self-reported activity $\operatorname{logs}$ to ensure consistency.

\section{Performance-Based Physical Function}

We used the 6-minute walking test $\left(6 \mathrm{MWT}^{36}\right)$ to measure the total distance in meters that participants walk in the span of 6 minutes while observed in the clinic. This test provides a snapshot of an individual's functional capacity and has demonstrated excellent reliability in patients with chronic pain. ${ }^{51}$ Higher distance traveled depicted higher physical function. We used a standardized method to prevent random error or reactivity. The test was performed in a closed, flat, oval indoor space marked in meter increments. Minimal and uniform encouragements were given to all participants. The same study staff performed both the baseline and post-program 6MWT.

\section{Patient-Reported Physical Function (Disability)}

We used the World Health Organization Disability Assessment Schedule (WHODAS 2.0) (World Health Organization, 2010) to assess patient reported physical function. This measure had previously been demonstrated to be valid in patient with chronic pain. ${ }^{52}$ The WHODAS 2.0 is a 36 -item scale assessing difficulty in performing various daily living activities in domains such as cognitions (understanding and communicating), mobility (eg, getting around), self-care (eg, hygiene, dressing), getting along and interacting with others, life activities (eg, household, leisure, school and work responsibilities), and participation (eg, community activities). Internal reliability for the WHODAS 2.0 in the current sample was excellent (Cronbach's alpha $=0.96$ ). High scores depict higher disability and lower physical function. For consistency herein we refer to this construct as "disability".

\section{Pain and Non-Adaptive Coping Strategies}

The Numerical Rating Scale (NRS) ${ }^{53,54}$ was used to measure pain intensity. This is a 2-item scale measuring pain intensity at rest and pain intensity during activity. High scores depict higher pain intensity.

The Pain Catastrophizing Scale (PCS) $)^{55}$ was used to measure participants' tendencies toward rumination, magnification and helplessness when faced with pain. The PCS has 13 items and had excellent internal reliability in our sample (Cronbach's alpha $=0.94$ ). High scores depict higher pain catastrophizing.

The Tampa Scale for Kinesiophobia (TSK) ${ }^{56}$ was used to measure fear of movement and physical activity due to pain. The TSK is a 17-item questionnaire and had good internal consistency (Cronbach's alpha $=0.86$ ). High scores depict higher levels of kinesiophobia.

\section{Adaptive Coping Strategies}

The Measures of Current Status (MOCS- ${ }^{57}$ ) was used to measure participants' abilities to use general coping efforts and strategies such relaxation, adaptive thinking, and social support. The MOCS-A is a 13-item questionnaire and had good internal reliability (Cronbach's alpha $=0.88$ ). High scores depict better use of coping strategies.

The Pain Resilience Scale (PRS) ${ }^{58}$ was used to capture participants' abilities to maintain behavioral engagement and regulate emotions in the face of pain. This is a 14-item measure and had good internal reliability in the current sample (Cronbach's alpha $=0.89$ ). High scores depict greater pain resilience.

The Cognitive and Affective Mindfulness Scale Revised (CAMS-R) ${ }^{59}$ was used to assess cognitive and affective aspects of mindfulness (ie, participants' abilities to pay attention to their experiences in the present moment in a non-judgmental manner). This is a 12-item questionnaire and had good internal reliability (Cronbach's alpha $=0.84$ ). High scores depict greater mindfulness.

\section{Social-Emotional Dysfunction}

The PROMIS anxiety (v1.08a) $)^{60}$ was used to measure anxiety symptoms. This is an 8-item questionnaire and had excellent internal reliability (Cronbach's alpha $=0.95$ ). High scores depict higher levels of anxiety.

The PROMIS depression (v1.08b) ${ }^{61}$ was used to measure symptoms of depression. This is an 8-item questionnaire and had excellent internal reliability (Cronbach's 
alpha $=0.96$ ). High scores depict higher levels of depression.

The PROMIS social isolation short form $(4 a)^{62}$ was used to capture patients' perceptions of being left out and disconnected from others. This is a 4-item questionnaire and had good internal reliability (Cronbach's alpha $=0.88$ ). High scores are indicative of social isolation.

The PROMIS emotional support $(4 a)^{63}$ was used to capture the availability of others with whom to talk to and feeling appreciated by others. This is a 4-item questionnaire and had excellent internal reliability (Cronbach's alpha $=0.92$ ). We reversed the scores on this measure such that high scores depict greater dysfunction.

\section{Statistical Analysis}

\section{Sample Characteristics and Correlations}

Data analyses were conducted in $R 3.6 .1 .^{64}$ We examined the sample for missing data. Of the entire $\mathrm{N}=95$ sample, one participant had missing data on the NRS pain at rest, and 15 participants had missing ActiGraph data $(\mathrm{N}=6$ dropped out and did not wear the ActiGraph; $\mathrm{N}=5$ had no valid wear days, and 4 had missing data due to a technical error). A total of $\mathrm{N}=79$ participants had full data for all study measures and were included in the main analyses, consistent with listwise requirements for structural equation modeling (SEM) ${ }^{65,66}$ We also verified normality (kurtosis $=0.49-0.53$, skewness $=0.25-0.27$ ) and the absence of univariate outliers to ensure the suitability of the data for SEM. Descriptive statistics were used to characterize the sample by study measures. Pearson correlations assessed the bivariate associations between the different measures of physical function. All measures were standardized to z-scores for subsequent latent variable analyses.

\section{Determining Latent Variable Structure}

Prior to SEM, we confirmed that our psychosocial measures had an underlying factor structure. Separate constructs for measures of pain and non-adaptive coping, adaptive coping, and social-emotional dysfunction were established using confirmatory factor analysis (CFA) with maximum likelihood estimation. This approach is widely used to evidence the validity of psychosocial constructs. ${ }^{67}$ Factors were retained as latent variables in the SEM if they met commonly accepted criteria: ${ }^{68}$ Bartlett's test of sphericity $(p<0.05)$, the Kaiser-Meyer-Olkin (KMO) measure of sampling adequacy $(>0.60)$, and loadings $\geq 0.40$.
Test of Measurement and Structural Models

SEM was conducted using the lavaan package in $R .^{69}$ SEM allowed us to build on the CFA by testing the hypothesized relationships between psychosocial latent variables (pain and non-adaptive coping, adaptive coping, and social-emotional dysfunction) and physical function measurements (objective, performance-based, and patient-reported). First, we developed a measurement model by assigning each measure to its respective latent variable from the CFA. Next, we tested the degree to which non-adaptive coping, adaptive coping, and socialemotional dysfunction were separate yet related psychosocial constructs. Finally, we entered physical function variables as single indicators and specified directional paths to each of the psychosocial latent variables. This allowed for examination of differential associations between physical function modality (objective, performance-based, and patient-reported) and latent variables (pain and non-adaptive coping, adaptive coping, socialemotional dysfunction), consistent with our research questions.

\section{Estimation and Model Fit}

Maximum likelihood estimation, which is the most commonly used method in SEM, ${ }^{67,70}$ was used to estimate all model parameters simultaneously. Decisions regarding model were based on commonly accepted criteria: ${ }^{71,72}$ Chi-square test of fit $(\mathrm{Cmin} / \mathrm{df})$ value near 2, a comparative fit index $(\mathrm{CFI}) ;^{73} \geq 0.95$, and the root-meansquare error approximation (RMSEA ${ }^{74}$ ) value between 0.002 and 0.08 . We considered each of these indices when interpreting goodness of fit as no single measure is considered a "gold standard". ${ }^{74,75}$ Within the model, correlation coefficients were used to measure the bidirectional strength of association between the psychosocial latent variables. Statistically significant regression coefficients (standardized beta values) suggest a directional relationship between the psychosocial latent variables and the physical function measures.

\section{Results}

\section{Preliminary Analyses}

Participants were generally sedentary ( $M$ daily step count of $\sim 5550$ steps $),{ }^{76}$ had lower performances on the 6MWT ( $\sim 350$ meters) ${ }^{51}$ and higher levels of disability on the WHODAS $2.0(\sim 32)^{7,77}$ compared to previously reported values in other chronic pain samples. Table 2 illustrates descriptive statistics for all study measures. 
Table 2 Descriptive Statistics for Study Measures

\begin{tabular}{|l|l|}
\hline & M (SD) \\
\hline ActiGraph average steps & $5548.63(2824.95)$ \\
6-minute walk test distance (m) & $348.23(89.96)$ \\
Physical function (WHODAS) & $31.26(18.72)$ \\
Pain at rest & $5.34(2.30)$ \\
Pain with activity & $7.05(2.02)$ \\
Pain catastrophizing & $21.63(12.06)$ \\
Kinesiophobia & $39.45(8.33)$ \\
Coping strategies & $26.91(9.28)$ \\
Pain resiliency & $34.29(10.10)$ \\
Mindfulness & $30.83(6.54)$ \\
Anxiety & $56.50(9.80)$ \\
Depression & $56.63(10.35)$ \\
Social isolation & $50.34(10.15)$ \\
Emotional support & $48.99(8.46)$ \\
\hline
\end{tabular}

Performance-based (6MWT) and objective (ActiGraph steps) physical function were significantly and moderately correlated ( $r=0.47, p<0.001$ ). Patient-reported disability (WHODAS) was not significantly correlated with performance-based ( $r=-0.19, p=0.09)$ or objective/ambulatory measured $(r=-0.18, p=0.11)$ physical function.

\section{Confirmatory Factor Analyses (CFA)}

Three CFAs were conducted to determine that the psychosocial measures loaded onto their respective constructs. The NRS (activity and rest), PCS, and TSK loaded onto the first factor for pain and non-adaptive coping (KMO = 0.70; Bartlett's test, $p<0.001$, standardized loadings $=$ $0.58-0.76$, variance explained $=44 \%$ ). The MOCS-A, PRS, and CAMS-R loaded onto the second factor for adaptive coping $(\mathrm{KMO}=0.61$; Bartlett's test, $p<0.001$, standardized loadings $=0.66-0.99$, variance explained $=$ 58\%). The PROMIS subscales of anxiety, depression, social isolation, and emotional support loaded onto the third factor for social-emotional dysfunction $(\mathrm{KMO}=$ 0.66; Bartlett's test, $p<0.001$, standardized loadings $=$ $0.33-0.90$, variance explained $=51 \%$ ). Pain and nonadaptive coping, adaptive coping, and social-emotional dysfunction were retained as the latent variables in subsequent SEM.

\section{Structural Equation Modeling (SEM)}

The measurement model, with the psychosocial measures loaded onto their respective latent variables, demonstrated adequate fit $(\mathrm{Cmin} / \mathrm{df}=1.57, \mathrm{CFI}=0.944, \mathrm{RMSEA}=$ 0.085). Next, we explored interrelationships between the psychosocial constructs before adding the physical activity measures. Prior to entering the physical function measures, the pain and non-adaptive coping factor was significantly negatively correlated with adaptive coping $(r=-0.57, p=$ $0.014)$ and significantly positively correlated with socialemotional dysfunction $(r=0.67, p=0.001)$. Higher adaptive coping and social-emotional dysfunction were also significantly and negatively correlated $(r=-0.79, p<0.001)$.

As illustrated in Figure 1, the 3 physical function measures were added to the model as indicators and directional paths were specified to assess the relationships between psychosocial latent variables and physical function measures. This final structural model retained adequate fit $(\mathrm{Cmin} / \mathrm{df}=1.39, \mathrm{CFI}=0.946$, RMSEA $=$ $0.070)$. Greater pain and non-adaptive coping $(\beta=0.68$, $p<0.001)$, social-emotional dysfunction $(\beta=0.65, p<$ $0.001)$, and adaptive coping $(\beta=-0.65, p<0.001)$ were all significantly associated with higher patient-reported disability. The latent variables for pain and non-adaptive coping, adaptive coping, or social-emotional dysfunction were not significantly correlated with the objective (range $\beta=-0.11-0.08$, range $p=0.390-0.639)$ nor performancebased (range $\beta=-0.18-0.028$, range $p=0.150-0.806$ ) measures of physical function.

\section{Discussion}

Improving all aspects of physical function (PROs, performance-based and objective/ambulatory measured) is an important goal of chronic pain treatments. Using SEM, we first tested to which extent the 3 types of physical function measurement are interrelated, and second, to what degree common psychological factors targeted within non-pharmacological clinical trials are associated with each of the 3 physical function measures.

Testing our first research question revealed that while the 6MWT and accelerometer-measured daily average step-count were moderately correlated, their correlation with disability was not statistically significant. This finding partially aligns with previous research, ${ }^{21,22}$ which identified little or no association between PRO physical function and accelerometer data. However, these 2 studies also found a significant association between PRO and performance-based physical function. This discrepancy may be due to differences in the PROs used to measure physical function, and use of different types of ActiGraph measures with different levels of accuracy and calibrations across the different studies. Our finding highlights the importance of assessing all facets of physical function (PRO, 


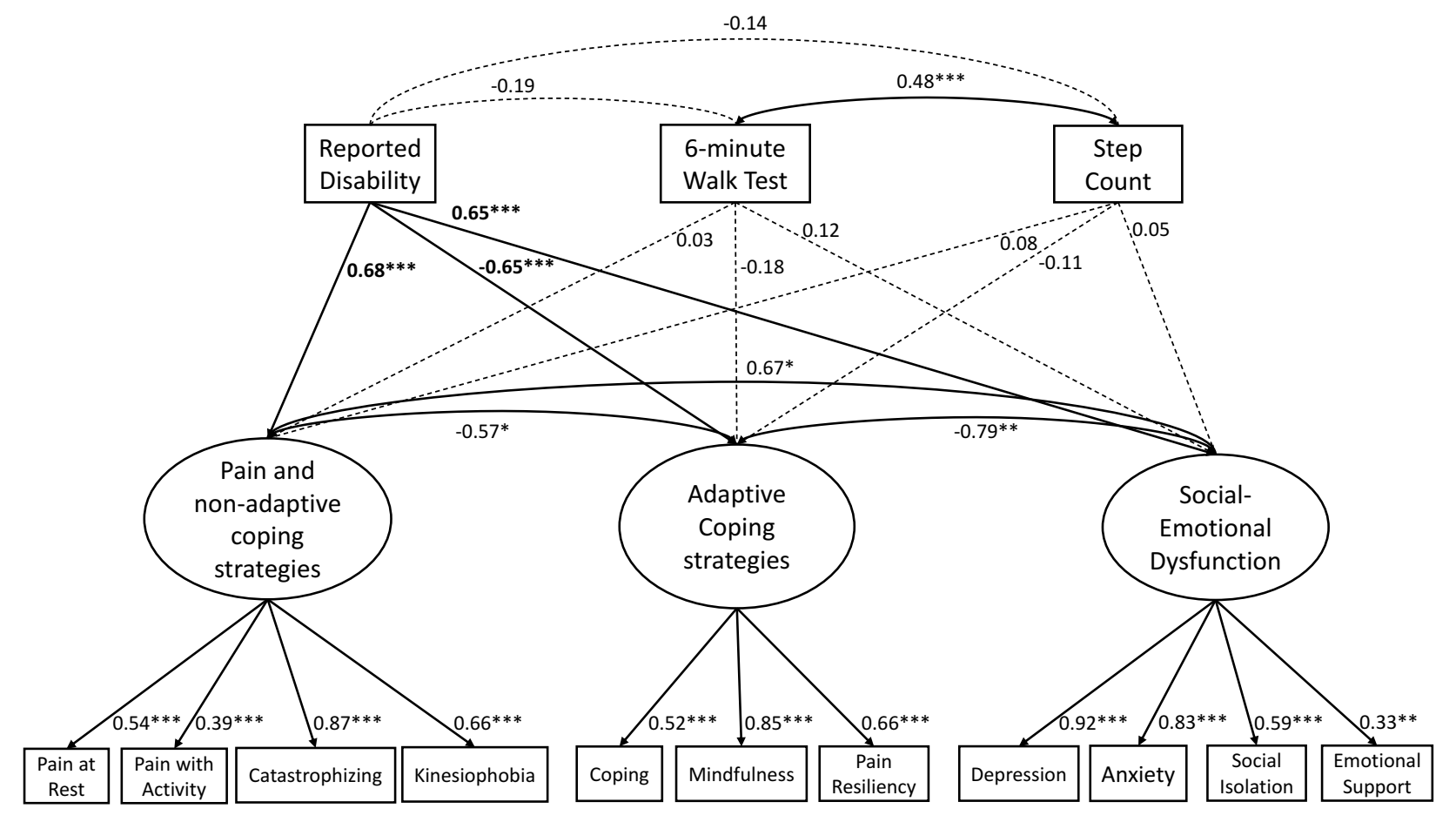

Figure I SEM model.

Notes: Structural model with directional paths specified from the 3 physical function measures to the psychosocial latent variables. Model fit was adequate (Cmin/df $=1.39$, $\mathrm{CFI}=0.946$, RMSEA $=0.070$ ). The bold values represent significant paths for the physical function measurements. The reported significance levels are standard as follows: $*_{p}<0.05, * *_{p}<0.01$, *** $p<0.001$.

functional capacity/performance-based and ambulatory measured step-count) which are not redundant but provide complementary information regarding an individual's overall physical function, and supports recommendations from IMMPACT and ICF.

Testing our second research question revealed that all latent psychosocial factors (ie, pain and non-adaptive coping, adaptive coping, and social-emotional dysfunction) significantly correlated with PRO physical function, while none correlated with 6MWT and objective/ambulatory physical function. This supports previous findings highlighting the multidimensionality of chronic pain ${ }^{25}$ and the link between psychosocial factors and PRO measured physical function ${ }^{8,26}$ but not objective/ambulatory-measured physical function, ${ }^{12,21,28}$ with associations with performance-based physical function being mixed. ${ }^{21,27,28,78}$ This finding further highlights the importance of a comprehensive assessment of all aspects of physical function. Our results confirm the potential of improvement in PRO physical function through commonly targeted psychosocial factors, while pointing to the need for additional targets in order to also improve functional capacity and ambulatory activity, which are important aspects of physical function with strong implications for morbidity and mortality.
Taken together, these findings have several important implications. It is important to include PROs, performance-based and objective measures of physical function, in line with IMMPACT criteria, ${ }^{8,9}$ as each provides important and unique information about particular aspects of physical function. ${ }^{21,22}$ Each measurement has its own advantages and limitations which should be taken into consideration in interventions for chronic pain. For instance, PROs provide information about the patient's perceptions and experiences, which are critical determinants of their well-being, ${ }^{79}$ but provide limited information regarding their functional capacity or ambulatory activity. Performance-based measures provide information on an individual's functional capacity during a timelimited test that may be influenced by an individual's motivation, without capturing other information regarding activity in the individual's day to day life. ${ }^{8}$ Accelerometers can provide useful and more objective activity estimates of an individual's ambulatory activity across a longer specified time period, ${ }^{80}$ but do not capture important activities of daily living such as dressing, eating, engagement in domestic activities, school or work, which are better captured by PROs. Further, accelerometers may pose a burden to participants and are limited to the degree to which they 
are worn, highlighting the importance of carefully designed research protocols to ensure reliable and valid assessment of step-count.

The lack of association between any of the common psychosocial intervention targets in chronic pain programs (eg, pain and non-adaptive coping, adaptive coping, and social-emotional function) and performance-based or objective measures of physical function suggests another implication - in order to improve patients' performance - and accelerometer-based physical function, other components are needed. IMMPACT recommends directly targeting increased activity, ${ }^{8}$ and current skills targeting activity such as setting activity goals, quota-based activity pacing and behavioral activation may be particularly promising. ${ }^{33,34}$ Using a commercially available digital monitoring device such as a Fitbit offers the potential to help individuals monitor their step count and reinforce activity goals. ${ }^{33,43}$ Finally, our findings highlight the extent of associations within measurement modalities and dissociations across measurement modalities. There were significant and mostly moderate-tostrong correlations across all of the patient-reported measures, regardless of the specific construct they were intended to assess. Patients' subjective experiences tend to converge and are evident across PROs. This offers numerous avenues through which interventions may be sensitive to patientreported outcomes but also conveys how little these relate to performance and objective physical function outcomes.

The current study has several strengths. First, it provides a rare comprehensive assessment of physical function among patients with chronic pain, using patientreported, performance-based and objective measures, in accordance with IMMPACT and ICF guidelines. ${ }^{8}$ Second, we used SEM to test relationships between variables. This approach enables concurrent examination of the relationships between a multitude of factors, as well as consideration of latent variables that cannot be directly observed. Third, we used step-count as our accelerometer output variable. Recent data suggest that step-count is better correlated with measures such as physical activity energy expenditure, ${ }^{81}$ compared to accelerometer activity intensity measures such as moderate-to-vigorous activity $\left(\mathrm{MVPA}^{81}\right)$. Importantly, step-count provides information regarding movement regardless of intensity, which may optimally capture the construct of physical function and performance of activities of daily living. Finally, to objectively measure step-count, we used hip-mounted ActiGraph accelerometers, which maximize accuracy and bypass the overestimation of steps in daily living associated with wrist-worn devices such as Fitbit. ${ }^{82,83}$

Some limitations of the study should also be considered. The sample size is small, and our model may have overfit our data. Our SEM approach may be seen as justified, nevertheless, given the relatively strong factor loadings and overall fit indices. Additionally, the latent variables were highly correlated with each other, raising some doubt about whether they represent distinct constructs. This is consistent with the significant overlap found between psychological measures in pain samples which may reflect patients' overall underlying emotional distress. ${ }^{84}$ The cross-sectional study design precludes the ability to determine causality in this study. Finally, generalizability may be limited by the fact that participants in this study had all signed up to participate in an intervention and were recruited from a single urban center. While testing the subsection of the population with chronic pain who are willing and able to participate in interventions may help inform treatment programs directed specifically at these patients, future studies may strengthen the current findings by testing participants from multiple sites and using larger samples with longitudinal assessments.

\section{Conclusion}

This study was the first to examine patient-reported, performance-based, and objective physical function along with commonly used psychosocial targets in a single model among patients with chronic pain. Findings confirm that patient-reported, performance-based, and objective assess different aspects of function. Targeting psychosocial variables such as pain and non-adaptive coping, adaptive coping, and social-emotional dysfunction has the potential to improve patient-reported physical function, but additional targets may be needed to improve patients' functional capacities and ambulatory activities. Future research can extend our findings by examining the longitudinal association between the 3 physical function assessments and the PROs during chronic pain interventions.

\section{Abbreviations}

$\mathrm{PF}$, physical function; IMMPACT, Initiative on Methods, Measurement, and Pain Assessment in Clinical Trials; ICF, International Classification of Functioning, Disability and Health; PRO, patient-reported outcomes; 6MWT, 6-minute walk test; WHODAS, World Health Organization Disability Assessment Schedule; NRS, Numerical Rating Scale; PCS, Pain Catastrophizing Scale; TSK, The Tampa 
Scale for Kinesiophobia; MOCS-A, The Measures of Current Status; PRS, Pain Resilience Scale; CAMS-R, Cognitive and Affective Mindfulness Scale - Revised; SEM, structural equation modeling; CFA, confirmatory factor analysis; KMO, Kaiser-Meyer-Olkin; RMSEA, root-mean-square error approximation.

\section{Author Contributions}

All authors made a significant contribution to the work reported, whether that is in the conception, study design, execution, acquisition of data, analysis and interpretation, or in all these areas; took part in drafting, revising or critically reviewing the article; gave final approval of the version to be published; have agreed on the journal to which the article has been submitted; and agree to be accountable for all aspects of the work.

\section{Funding}

This study was funded by an R34 grant from the National Center for Complementary and Integrative Health (1R34AT009356-01A1) to the senior author.

\section{Disclosure}

The authors declare that they have no conflicts of interest.

\section{References}

1. Phillips CJ. The cost and burden of chronic pain. Rev Pain. 2009;3 (1):2-5. doi:10.1177/204946370900300102

2. Turk DC, Dworkin RH, Revicki D, et al. Identifying important outcome domains for chronic pain clinical trials: an IMMPACT survey of people with pain. Pain. 2008;137(2):276-285. doi:10.1016/j. pain.2007.09.002

3. Poulin PA, Romanow HC, Rahbari N, et al. The relationship between mindfulness, pain intensity, pain catastrophizing, depression, and quality of life among cancer survivors living with chronic neuropathic pain. Support Care Cancer. 2016;24(10):4167-4175. doi:10.1007/ s00520-016-3243-x

4. Dowell D, Haegerich TM, Chou R. CDC guideline for prescribing opioids for chronic pain-United States, 2016. JAMA. 2016;315 (15):1624-1645. doi:10.1001/jama.2016.1464

5. Jackson W, Kulich R, Malacarne A, Lapidow A, Vranceanu A. (497) Physical functioning and mindfulness based interventions in chronic pain: a systematic review. J Pain. 2016;17(4):S99. doi:10.1016/j. jpain.2016.01.304

6. Rodríguez-Blázquez C, Damián J, Andrés-Prado $\mathrm{MJ}$, et al. Associations between chronic conditions, body functions, activity limitations and participation restrictions: a cross-sectional approach in Spanish non-clinical populations. BMJ Open. 2016;6(6):e010446. doi:10.1136/bmjopen-2015-010446

7. Tarvonen-Schröder S, Kaljonen A, Laimi K. Comparing functioning in spinal cord injury and in chronic spinal pain with two ICF-based instruments: WHODAS 2.0 and the WHO minimal generic data set covering functioning and health. Clin Rehabil. 2019;33(7):1241-1251. doi:10.1177/0269215519839104
8. Taylor AM, Phillips K, Patel KV, et al. Assessment of physical function and participation in chronic pain clinical trials: IMMPACT/OMERACT recommendations. Pain. 2016;157:1836-1850. doi:10.1097/j.pain. 0000000000000577

9. Gewandter JS, Dworkin RH, Turk DC, et al. Improving study conduct and data quality in clinical trials of chronic pain treatments: IMMPACT recommendations. $J$ Pain. 2019. doi:10.1016/j. jpain.2019.12.003

10. World Health Organization. International Classification of Functioning, Disability and Health (ICF). Geneva; 2001.

11. Smuck M, Tomkins-Lane C, Ith MA, Jarosz R, Kao MCJ. Physical performance analysis: a new approach to assessing free-living physical activity in musculoskeletal pain and mobility-limited populations. PLoS One. 2017;12(2):e0172804. doi:10.1371/journal.pone.0172804

12. Huijnen IPJ, Verbunt JA, Peters ML, et al. Do depression and pain intensity interfere with physical activity in daily life in patients with chronic low back pain? Pain. 2010;150(1):161-166. doi:10.1016/j. pain.2010.04.021

13. Pryce R, Johnson M, Goytan M, Passmore S, Berrington N, Kriellaars D. Relationship between ambulatory performance and self-rated disability in patients with lumbar spinal stenosis. Spine (Phila Pa 1976). 2012;37 (15):1316-1323. doi:10.1097/BRS.0b013e31824a8314

14. Vanbuskirk K, Roesch S, Afari N, Wetherell JL. Physical activity of patients with chronic pain receiving acceptance and commitment therapy or cognitive behavioural therapy. Behav Chang. 2014;31 (2):131-143. doi:10.1017/bec.2014.6

15. Wideman TH, Finan PH, Edwards RR, et al. Increased sensitivity to physical activity among individuals with knee osteoarthritis: relation to pain outcomes, psychological factors, and responses to quantitative sensory testing. Pain. 2014;155(4):703-711. doi:10.1016/j.pain. 2013.12.028

16. Dunlop DD, Song J, Semanik PA, Sharma L, Chang RW. Physical activity levels and functional performance in the osteoarthritis initiative: a graded relationship. Arthritis Rheum. 2011;63(1):127-136. doi: $10.1002 /$ art. 27760

17. Terwee CB, van der Slikke RMA, van Lummel RC, Benink RJ, Meijers WGH, de Vet HCW. Self-reported physical functioning was more influenced by pain than performance-based physical functioning in knee-osteoarthritis patients. J Clin Epidemiol. 2006;59 (7):724-731. doi:10.1016/j.jclinepi.2005.11.019

18. Guildford BJ, Jacobs CM, Daly-Eichenhardt A, Scott W, McCracken LM. Assessing physical functioning on pain management programmes: the unique contribution of directly assessed physical performance measures and their relationship to self-reports. $\mathrm{Br}$ J Pain. 2017;11(1):46-57. doi:10.1177/2049463716680559

19. Terrier P, Le Carre J, Connaissa ML, Leger B, Luthi F. Monitoring of gait quality in patients with chronic pain of lower limbs. IEEE Trans Neural Syst Rehabil Eng. 2017;25(10):1843-1852. doi:10.1109/ TNSRE.2017.2688485

20. Feinglass J, Song J, Semanik P, et al. Association of functional status with changes in physical activity: insights from a behavioral intervention for participants with arthritis. Arch Phys Med Rehabil. 2012;93(1):172-175. doi:10.1016/j.apmr.2011.06.037

21. Alschuler KN, Hoodin F, Murphy SL, Geisser ME. Ambulatory monitoring as a measure of disability in chronic low back pain populations. Clin J Pain. 2011;27(8):707-715. doi:10.1097/ AJP.0b013e318217b7d0

22. Conway J, Tomkins CC, Haig AJ. Walking assessment in people with lumbar spinal stenosis: capacity, performance, and self-report measures. Spine J. 2011;11(9):816-823. doi:10.1016/j.spinee.2010.10.019

23. Sander L, Paganini S, Lin J, et al. Effectiveness and cost-effectiveness of a guided Internet- and mobile-based intervention for the indicated prevention of major depression in patients with chronic back pain-study protocol of the PROD-BP multicenter pragmatic RCT. BMC Psychiatry. 2017;17(1). doi:10.1186/s12888-0171193-6 
24. Wertli MM, Burgstaller JM, Weiser S, Steurer J, Kofmehl R, Held U. Influence of catastrophizing on treatment outcome in patients with nonspecific low back Pain: a systematic review. Spine (Phila Pa 1976). 2014;39:263-273. doi:10.1097/BRS.0000000000000110

25. Tagliaferri SD, Miller CT, Owen PJ, et al. Domains of chronic low back pain and assessing treatment effectiveness: a clinical perspective. Pain Pract. 2020;20(2):211-225. doi:10.1111/papr.12846

26. Bergbom S, Boersma K, Overmeer T, Linton SJ. Relationship among pain catastrophizing, depressed mood, and outcomes across physical therapy treatments. Phys Ther. 2011;91(5):754-764. doi:10.2522/ ptj.20100136

27. Igwesi-Chidobe $\mathrm{CN}$, Coker $\mathrm{B}$, Onwasigwe $\mathrm{CN}$, Sorinola IO, Godfrey EL. Biopsychosocial factors associated with chronic low back pain disability in rural Nigeria: a population-based crosssectional study. BMJ Glob Heal. 2017;2(3). doi:10.1136/bmjgh-2017-000284

28. Tonelli SM, Rakel BA, Cooper NA, Angstom WL, Sluka KA. Women with knee osteoarthritis have more pain and poorer function than men, but similar physical activity prior to total knee replacement. Biol Sex Differ. 2011;2(1):12. doi:10.1186/2042-6410-2-12

29. Carvalho FA, Maher CG, Franco MR, et al. Fear of movement is not associated with objective and subjective physical activity levels in chronic nonspecific low back pain. Arch Phys Med Rehabil. 2017;98 (1):96-104. doi:10.1016/j.apmr.2016.09.115

30. Janevic M, Kratz A, Piette J, Murphy S. How are fear-avoidance beliefs associated with objectively-measured physical activity level in osteoarthritis patients? J Pain. 2018;19(3):S34. doi:10.1016/j. jpain.2017.12.090

31. Sharpe L, Jones E, Ashton-James CE, Nicholas MK, Refshauge K. Necessary components of psychological treatment in pain management programs: a Delphi study. Eur J Pain. 2020;24(6):1160-1168. doi:10.1002/ejp.1561

32. McCracken LM. Necessary components of psychological treatment for chronic pain: more packages for groups or process-based therapy for individuals? Eur J Pain. 2020;24(6):1001-1002. doi:10.1002/ejp.1568

33. Greenberg J, Lin A, Zale EL, et al. Development and early feasibility testing of a mind-body physical activity program for patients with heterogeneous chronic pain; the GetActive study. $J$ Pain Res. 2019;12:3279-3297. doi:10.2147/JPR.S222448

34. Greenberg J, Popok PJ, Lin A, et al. A mind-body physical activity program for chronic pain with or without a digital monitoring device: proof-of-concept feasibility randomized controlled trial. JMIR Form Res. 2020;4(6):e18703. doi:10.2196/18703

35. IASP Taxonomy Working Group. Pain Terms a Current List with Definitions and Notes on Usage; 1986.

36. American Thoractic Society. ATS statement: the six-minute walk test. Am J Respir Crit Care Med. 2002;166(1):111-117. doi:10.1164/ rccm.166/1/111.

37. Sullivan MJL, Thorn B, Haythornthwaite JA, et al. Theoretical perspectives on the relation between catastrophizing and pain. Clin J Pain. 2001;17(1):52-64. doi:10.1097/00002508-200103000-00008

38. Moseley GL, Vlaeyen JWS. Beyond nociception: the imprecision hypothesis of chronic pain. Pain. 2015;156:35-38. doi:10.1016/j. pain.0000000000000014

39. Verhiel SHWL, Greenberg J, Zale EL, Chen NC, Ring DC, Vranceanu AM. What role does positive psychology play in understanding pain intensity and disability among patients with hand and upper extremity conditions? Clin Orthop Relat Res. 2019;477 (8):1769-1776. doi:10.1097/CORR.0000000000000694

40. Flink IK, Smeets E, Bergbom S, Peters ML. Happy despite pain: pilot study of a positive psychology intervention for patients with chronic pain. Scand J Pain. 2015;7:71-79. doi:10.1016/j.sjpain.2015.01.005

41. Shapero BG, Greenberg J, Pedrelli P, Desbordes G, Lazar SW. Mindfulness-based cognitive therapy. In: Shapero BG, Mischoulon D, Cusin C, editors. The Massachusetts General Hospital Guide to Depression. New York, NY: Springer; 2018:167-177.
42. Shapero BG, Greenberg J, Pedrelli P, de Jong M, Desbordes G. Mindfulness-based interventions in psychiatry. Focus (Madison). 2018;16(1):32-39. doi:10.1176/appi.focus.20170039

43. Jackson W, Zale EL, Berman SJ, et al. Physical functioning and mindfulness skills training in chronic pain: a systematic review. $J$ Pain Res. 2019;12:179-189. doi:10.2147/JPR.S172733

44. Weinberger DA, Bartholomew K. Social-emotional adjustment and patterns of alcohol use among young adults. J Pers. 1996;64 (2):495-527. doi:10.1111/j.1467-6494.1996.tb00519.x

45. Riggs NR, Jahromi LB, Razza RP, Dillworth-Bart JE, Mueller U. Executive function and the promotion of social-emotional competence. J Appl Dev Psychol. 2006;27(4):300-309. doi:10.1016/ j.appdev.2006.04.002

46. Elias MJ, O'brien MU, Weissberg RP. Transformative Leadership for Social-Emotional Learning. Princ Leadersh; 2006.

47. Cain KL, Conway TL, Adams MA, Husak LE, Sallis JF. Comparison of older and newer generations of ActiGraph accelerometers with the normal filter and the low frequency extension. Int J Behav Nutr Phys Act. 2013;10:51. doi:10.1186/1479-5868-10-51

48. Knuth ND, Chen KM, Schrack JA. Objectively measured physical activity varies by task and accelerometer location in younger and older adults. Med Sci Sport Exerc. 2016;48:1061. doi:10.1249/01. mss.0000488192.95209.a5

49. Evenson KR, Wen F. Performance of the ActiGraph accelerometer using a national population-based sample of youth and adults. BMC Res Notes. 2015;8(1):7. doi:10.1186/s13104-0140970-2

50. Aadland E, Ylvisåker E. Reliability of the actigraph GT3X+ accelerometer in adults under free-living conditions. PLoS One. 2015;10 (8):e0134606. doi:10.1371/journal.pone.0134606

51. Pankoff BA, Overend TJ, Lucy SD, White KP. Reliability of the six-minute walk test in people with fibromyalgia. Arthritis Rheum. 2000;13(5):291-295. doi:10.1002/1529-0131(200010)13:5<291::aidanr8>3.0.co;2-x

52. Wawrzyniak KM, Finkelman M, Schatman ME, et al. The world health organization disability assessment schedule-2.0 (WHODAS 2.0) in a chronic pain population being considered for chronic opioid therapy. J Pain Res. 2019;12:1855-1862. doi:10.2147/JPR. S207870

53. Farrar JT, Young JP, LaMoreaux L, Werth JL, Poole RM. Clinical importance of changes in chronic pain intensity measured on an 11-point numerical pain rating scale. Pain. 2001;94(2):149-158. doi:10.1016/S0304-3959(01)00349-9

54. Rodriguez CS. Pain measurement in the elderly: a review. Pain Manag Nurs. 2001;2(2):38-46. doi:10.1053/jpmn.2001.23746

55. Sullivan MJL, Bishop SR, Pivik J. The pain catastrophizing scale: development and validation. Psychol Assess. 1995;7(4):524-532. doi:10.1037/1040-3590.7.4.524

56. Woby SR, Roach NK, Urmston M, Watson PJ. Psychometric properties of the TSK-11: a shortened version of the Tampa Scale for Kinesiophobia. Pain. 2005;117(1-2):137-144. doi:10.1016/j.pain.2005.05.029

57. Carver CS: MOCS (Measure of Current Status). Available from: http://www.psy.miami.edu/faculty/ccarver/sclMOCS.html. Accessed June 19, 2019.

58. Slepian PM, Ankawi B, Himawan LK, France CR. Development and initial validation of the pain resilience scale. J Pain. 2016;17 (4):462-472. doi:10.1016/j.jpain.2015.12.010

59. Feldman G, Hayes A, Kumar S, Greeson J, Laurenceau JP. Mindfulness and emotion regulation: the development and initial validation of the Cognitive and Affective Mindfulness Scale-Revised (CAMS-R). J Psychopathol Behav Assess. 2007;29 (3):177-190. doi:10.1007/s10862-006-9035-8

60. Outcomes Measurement Information System. 2015. A Brief Guide to the PROMIS Anxiety Instruments. Available from: http://www.health measures.net/images/PROMIS/manuals/PROMIS_Anxiety_Scoring Manual.pdf. Accessed July 10, 2020. 
61. A brief guide to the PROMIS depression instruments. Patient Reported Outcomes Measurement Information System. Available from: http://www.healthmeasures.net/images/PROMIS/manuals/ PROMIS_Depression_Scoring_Manual.pdf. Accessed July 10, 2020.

62. A brief guide to the PROMIS Social Isolation instruments. Outcomes Measurement Information System. Available from: http://www.health measures.net/administrator/components/com_instruments/uploads/ 15-09-01_16-44-48_PROMISSocialIsolationScoringManual.pdf. Accessed October 29, 2018.

63. A brief guide to the PROMIS Emotional Support instruments. Outcomes Measurement Information System. Available from: https://www.assess mentcenter.net/documents/PROMISEmotionalSupportScoringManual. pdf. Accessed October 29, 2018.

64. R Development Core Team. R: a language and environment for statistical computing. R Found Stat Comput. 2019. doi:10.1017/ CBO9781107415324.004

65. Allison PD. Missing data techniques for structural equation modeling. J Abnorm Psychol. 2003;112(4):545-557. doi:10.1037/ 0021-843X.112.4.545

66. Curran C, Williams AC, Potts HWW. Cognitive-behavioral therapy for persistent pain: does adherence after treatment affect outcome? Eur J Pain. 2009;13(2):178-188. doi:10.1016/j.ejpain.2008.06.009

67. Li CH. Confirmatory factor analysis with ordinal data: comparing robust maximum likelihood and diagonally weighted least squares. Behav Res Methods. 2016;48(3):936-949. doi:10.3758/s13428-0150619-7

68. Budaev SV. Using principal components and factor analysis in animal behaviour research: caveats and guidelines. Ethology. 2010;116 (5):472-480. doi:10.1111/j.1439-0310.2010.01758.x

69. Rosseel Y. Lavaan: an R package for structural equation modeling. J Stat Softw. 2012;48. doi:10.18637/jss.v048.i02.

70. Kline RB. Principles and Practice of Structural Equation Modeling. New York: Guilford Press; 1998.

71. Hooper D, Coughlan J, Mullen M. Structural equation modelling: guidelines for determining model fit. Electron J Bus Res Methods. 2008;6(1):53-59. doi:10.1037/1082-989X.12.1.58

72. Hu LT, Bentler PM. Cutoff criteria for fit indexes in covariance structure analysis: conventional criteria versus new alternatives. Struct Equ Model. 1999;6(1):1-55. doi:10.1080/10705519909540118

73. Bentler PM, Bonett DG. Significance tests and goodness of fit in the analysis of covariance structures. Psychol Bull. 1980;88(3):588-606. doi:10.1037/0033-2909.88.3.588
74. Browne MW, Cudeck R. Alternative ways of assessing model fit. In: Bollen KA, Long JS, editors. Testing Structural Equation Models. Newbury Park, NJ: Sage; 1993:136-162.

75. Martens MP. The use of structural equation modeling in counseling psychology research. Couns Psychol. 2005;33(3):269-298. doi: $10.1177 / 0011000004272260$

76. Tudor-Locke C, Craig CL, Thyfault JP, Spence JC. A step-defined sedentary lifestyle index: $<5000$ steps/day. Appl Physiol Nutr Metab. 2013;38(2):100-114. doi:10.1139/apnm-2012-0235

77. Silva C, Coleta I, Silva AG, et al. Adaptation and validation of WHODAS 2.0 in patients with musculoskeletal pain. Rev Saude Publica. 2013;47(4). doi:10.1590/S0034-8910.2013047004374

78. Latorre-Román P, Santos-Campos M, Heredia-Jimenez J, DelgadoFernández M, Soto-Hermoso V. Analysis of the performance of women with Fibromyalgia in the six-Minute Walk Test and its relation with health and quality of life. J Sports Med Phys Fitness. 2014;54:511-517.

79. Kim JM, Stewart R, Glozier N, et al. Physical health, depression and cognitive function as correlates of disability in an older Korean population. Int $J$ Geriatr Psychiatry. 2005;20(2):160-167. doi:10.1002/gps.1266

80. Kelly LA, McMillan DGE, Anderson A, Fippinger M, Fillerup G, Rider J. Validity of actigraphs uniaxial and triaxial accelerometers for assessment of physical activity in adults in laboratory conditions. BMC Med Phys. 2013;13(1). doi:10.1186/1756-6649-13-5

81. Chomistek AK, Yuan C, Matthews CE, et al. Physical Activity Assessment with the ActiGraph GT3X and Doubly Labeled Water. Med Sci Sports Exerc. 2017;49(9):1935-1944. doi:10.1249/ MSS.0000000000001299

82. Chu AHY, Ng SHX, Paknezhad M, et al. Comparison of wrist-worn Fitbit Flex and waist-worn ActiGraph for measuring steps in free-living adults. PLoS One. 2017;12(2):e0172535. doi:10.1371/ journal.pone. 0172535

83. Feehan LM, Geldman J, Sayre EC, et al. Accuracy of fitbit devices: systematic review and narrative syntheses of quantitative data. JMIR MHealth UHealth. 2018;6(8):e10527. doi:10.2196/10527

84. Campbell P, Bishop A, Dunn KM, Main CJ, Thomas E, Foster NE. Conceptual overlap of psychological constructs in low back pain. Pain. 2013;154(9):1783-1791. doi:10.1016/j.pain.2013.05.035
Journal of Pain Research

\section{Publish your work in this journal}

The Journal of Pain Research is an international, peer reviewed, open access, online journal that welcomes laboratory and clinical findings in the fields of pain research and the prevention and management of pain. Original research, reviews, symposium reports, hypothesis formation and commentaries are all considered for publication. The manuscript

Submit your manuscript here: https://www.dovepress.com/journal-of-pain-research-journal management system is completely online and includes a very quick and fair peer-review system, which is all easy to use. Visit http:// www.dovepress.com/testimonials.php to read real quotes from published authors. 